\title{
Smart Grid Network Transmission Line RLC Modelling Using Random Power Line Synthesis Scheme
}

\author{
Ezennaya S.O ${ }^{1}$, Udeze C. C ${ }^{2}$, Okafor K .C ${ }^{3}$ \\ ${ }^{2,3} \mathrm{R} \&$ D Department, Electronics Development Institute \\ (FMST-NASENI), Awka, Nigeria.
}

\author{
Onyedikachi S.N ${ }^{4}$, Anierobi C.C ${ }^{5}$ \\ 1, 4, 5 Electronics Engineering Department, Nnamdi \\ Azikiwe University, Awka, Nigeria.
}

\begin{abstract}
This work proposes Random Power line Synthesis (RPLS) as a quicker computational approach to solving RLC parameters of a modern smart grid transmission network. Since modern grid systems provide a holistic perspective of modern grid development, it is obvious that a transmission network that is ageing cannot serve the expanded load demand. The need to revoltionalize the traditional transmission model while exploiting basic electrical theories and principles in Smart Grid (SG) architecture necessitated this paper. This work seeks to address the RLC parameter modelling for SG template to provision dynamic power in Nigerian context. Other schemes of transmission RLC modelling were studied as well as outlining their limitations. Consequently, we then proposed a fuzzy smart grid framework for RLC computation and developed a proposed SG overhead transmission line from its conductor characteristics and tower geometry considering the RLC parameters of the conductor while applying RPLS to generate the parameter metrics.
\end{abstract}

Keywords-RPLS; Smart Grid; Overhead; Conductor; RLC parameters.

\section{INTRODUCTION}

Generically, an electric grid consist of three main subsystems viz: The generation sources, delivery systems (transmission and distribution networks) and the end consumers. In Nigerian context, the ageing transmission power grids, opertional challenges and high unreliablity index characterises the grid network. This paper observes that the deregulation of the power sector will unleach unprecedented power (energy) trading across the regional power grids as such presenting power flow senarios and complexities in vendor interfaces which the system may not be able to handle. Essentially, the transmission line transmits electrical power from one end of the line, sending end, to another, receiving end. A common method of analyzing this behavior is through parameterization and modeling of the transmission lines with passive components [1]. In a transmission model, the interconnection must incorporate distributed self and mutual inductance to accurately estimate time delay and crosstalk metrics in a multilevel network for large scale integration. Besides, the towers and conductors of a transmission line are familiar elements in any given scenario. However, on closer inspection, each transmission line has unique characteristics that have correspondingly unique implications for the environment.
The scope of this paper is majorly on the computational intelligence of RPLS based on fuzzy logic framework. Our proposed RPLS framework optimizes real time computation of required transmission line parameters while computing the vector metrics just in time. This paper defines RPLS computational intelligence in this context to be the maximum number of simultaneous, bidirectional transmission line parameter inputs into the fuzzy line inference system that can be supported in the SG architecture.

The paper is organized as follows: In section II, the related works covering the overview of transmission line specifications, the Smart grid architecture, etc was presented. The general system model and assumptions for RPLS for SG transmission line was presented in III. In IV, The RPLS fuzzy logic framework mechanism is presented alongside with the analytical models. Section $\mathrm{V}$ gives the the simulation results to support our propositions. The paper ends with the conclusions and future directions.

All standard paper components have been specified for three reasons: (1) ease of use when formatting individual papers, (2) automatic compliance to electronic requirements that facilitate the concurrent or later production of electronic products, and (3) conformity of style throughout the proceedings. Margins, column widths, line spacing, and type styles are built-in; examples of the type styles are provided throughout this document and are identified in italic type, within parentheses, following the example.

\section{RELATED WORKS}

\section{A. Methods of Transmission Line Computational Analysis}

A representative sample of works on the methods of computing transmission line parameters have been studied in literature. The use of distributed-parameter state variable approach, State-space modelling of transposed lines using modal decomposition [2], lumped parameter approximation of line losses [2], distributed transmission line parameters [3], state equations [4], Compact Distributed RLC Interconnect Models [5] to compute line parameters as well as transients on transmission lines have been studied. Some observed limitations of these schemes include:

1) They involve complex mathematical models which could be lacking in precision and accuracy. 
2) Computational requirements for transmission line parameters is quiet large for scaled systems

3) These methods do not use any knowledge of the interior structure of the transmission model and in most cases allow only limited control of the closed-loop behaviour when feedback control is used in the parameter modelling. This work then proposed an intelligent approach to solving transmission line parameters. In the next sections, we shall introduce the line specification, smart grid architecture and the factors that limit maximum power transfer in a $S G$ transmission line.

\section{B. Transmission Line Specifications}

The work in [6], listed the design specifications (line characteristics) that are commonly required to define a transmission line. Many of these specifications could have their implications on the environmental as a whole. For the purpose of this work, a range of values is considered for these specifications, with the exception that a varying nominal voltage above $25 \mathrm{kV}$ is assumed. The most basic descriptive specifications usually will include a line name or other identifier, nominal voltage, length of line, altitude range, and the design load district. They details as follows viz [6]:

\section{1) Tower Specifications}

The towers support the conductors and provide physical and electrical isolation for energized lines. The minimum set of specifications for towers are the material of construction, type or geometry, span between towers, weight, number of circuits, and circuit configuration. At $500 \mathrm{kV}$, the material of construction is generally steel, though aluminium and hybrid construction, which uses both steel and aluminium, could be used. The type of tower refers to basic tower geometry. The options are lattice, pole (or monopole), $\mathrm{H}$-frame, guyed-V, or guyed-Y. The span is commonly expressed in the average number of towers per mile. This value ranges from four to six towers per mile. Also, the weight of the tower varies substantially with height, duty (straight run or corner, river crossing, etc.), material, number of circuits, and geometry.

\section{2) Transmission Tower Minimum Clearances}

The basic function of the tower is to isolate conductors from their surroundings, including other conductors and the tower structure in any deployment. In every design, clearances are specified for phase-to-tower, phase-to-ground, and phaseto-phase. For various line parameters, the Phase-to-tower clearances vary in distance ranges depending on specifications. These distances are maintained by insulator strings and must take into account possible swaying of the conductors. The typical phase-to-ground clearance is 30 to 40 feet. This clearance is maintained by setting the tower height, controlling the line temperature to limit sag, and controlling vegetation and structures in the ROW. Typical phase-to-phase separation is also 30 to 40 feet and is controlled by tower geometry and line motion suppression.

\section{3) Transmission Line Insulators}

Basically, insulator design varies according to tower function types. For suspension towers (line of conductors is straight), the insulator assembly is called a suspension string. For deviation towers (the conductors change direction), the insulator assembly is called a strain string. For $500-\mathrm{kV}$ lines, the insulator strings are built up from individual porcelain disks typically 5.75 inches thick and 10 inches in diameter. The full string is composed of 18 to 28 disks, providing a long path for stray currents to negotiate to reach ground. At this voltage, two to four insulator strings are commonly used at each conductor connection point, often in a $\mathrm{V}$ pattern to limit lateral sway.

\section{4) Transmission Lightning Protection}

Since the towers are tall with well-grounded metallic structures, lightning usually targets its structure creating unsolicited risk for end user electrical facilities/equipments. To control the effects of lightning, an extra set of wires is generally strung along the extreme top points of the towers. These wires are attached directly to the towers (no insulation), providing a path for the lightning directly to and through the towers to the ground straps at the base of the towers. The extra wires are called shield wires and are either steel or aluminiumclad steel with a diameter of approximately $1 / 2$ inch.

\section{5) Transmission Line Conductor Motion Suppression}

Wind-induced conductor motion, aeolian vibration, can damage the conductors. A variety of devices have been employed to dampen these oscillatory motions. Dampers can prevent the formation of standing waves by absorbing vibration energy. Typically, a single damper is located in each span for each conductor.

Some of the transmission line components include:

1) The Transmission towers which are the most visible component of the bulk power transmission system. Their function is to keep the high-voltage conductors separated from their surroundings and from each other. Higher voltage lines require greater separation. Some of the environmental implications of a transmission line result directly from these transmission tower design requirements. First, the physical dimensions of the towers, the resulting line arrangements and line spacing establish the necessary minimum dimensions, including clearances to natural and man-made structures. To create and maintain these clearances, it is often necessary to remove or trim vegetation during construction and operation. In addition, excavation, concrete pouring, and pile driving are required to establish foundations. All of these tasks require access roads and service facilities with dimensions and strength sufficient to handle large, heavy tower components, earthmoving equipment, and maintenance equipment.

Figure 1a shows a lattice-type tower with a single-circuit $765-\mathrm{kV}$ line with twelve conductors strung from insulators suspended on the crossbar as a single-circuit line. Figure $1 \mathrm{~b}$ shows a shared corridor for a typical transmission line.

\section{2) Conductors}

In this regard, various materials like copper, aluminium material which has higher strength to weight ratio is preferable for deployments. Typical aluminium conductors are composed of multiple 1/8-inch-thick strands twisted together. There are about 50 varieties of multi-strand conductor cables, but a variety of conductor compositions and constructions are currently in use to meet a variety of specific requirements. 
In designing and deploying a transmission infrastructure, the tower and its conductor geometry must be given utmost consideration in the capacity planning phase. Given the challenges of the traditional grid network for power provisioning, this thesis proposes Smart Grid power model for dynamic power stability in Nigeria. The two fundamental questions presented in this work $\left(\boldsymbol{Q}_{\boldsymbol{n}}\right)$ are viz:

1) What is Smart Grid-SG?

2) How does the RLC parameter modelling leverage on $S G$ to provision dynamic power in Nigeria context?

Firstly, the work proposes the modernization of the current electric power grid by leveraging on smart grid technology and conseqently models the RLC parameters of a SG overhead transmission line from its conductor characteristics and tower geometry. The next section starts with the concept of Smart Grid.

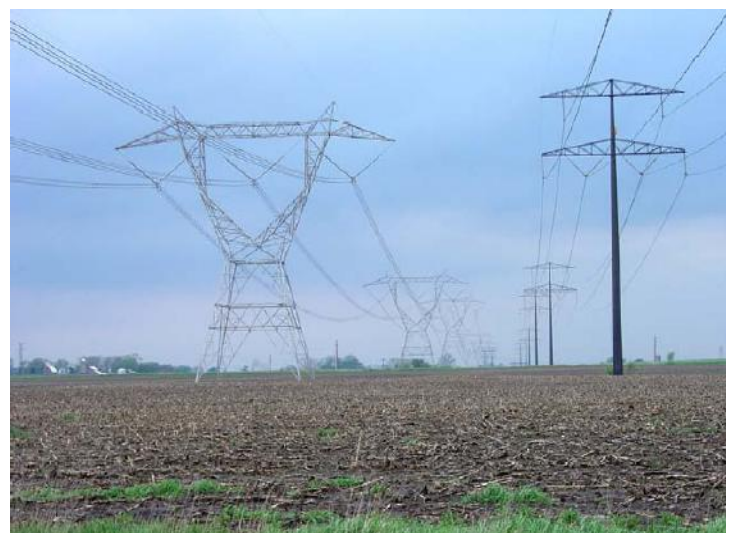

Fig.1. a. Lattice (left) and Monopole (right) Towers (Source: Argonne Staff Photo)

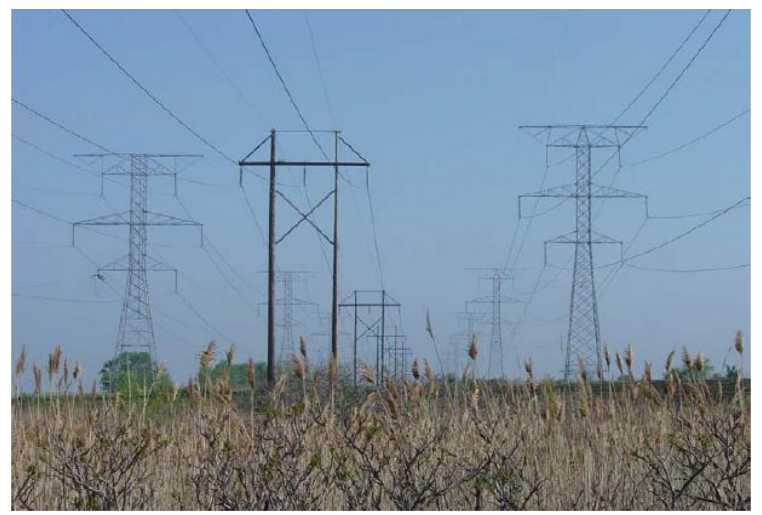

Fig.1. b: Multiple lines in a power Corridor (Source: Argonne Staff Photo)

\section{Smart Grid Architecture}

The concept of SG is relatively new vis-à-vis transmission line designs. Explicit definitions on $\mathrm{SG}$ has been given in [7],[8],[9],[10],[11],[12], and [13]. In context, this paper defines SG as a highly scalable, robost and intelligent power network that provides reliable, high quality electric power in an environmentally friendly and sustainable way. According to
[14], the scope of SG extends all the uinterconnected electic power systems, from centralized bulk generation to distribution, from high voltage transmission systems to low voltage distribution systems, from utility control centers to end user home-area networks, from bulk power market to demand response service provider, and from traditional energy rsources to distributed and renewable generatuion and storage. Table 1, shows the differences between the current power grid network and the SG network. The work in [14] presents five generic key technology areas (KTAs) as shown in figure 2.They includes:

1) Integrated Communications which supports broadband networks, secure, low-latency channels connecting transmission stations and control centers.

2) Sensing and Measurements which handles phasor measurements and data streaming over high speed channels

3) Advance Components which includes the flexible AC transmission system (FACTs) devics, eg.Unified power flow controllers (UPFC), Static Var compensations (SVC), static synchronous compensators and High Voltage DC (HVDC).

4) Advance Control and protection methods which includes differential line relaying, adaptive settings, and system integrity systems that supports low latency communications.

5) Enhanced interfaces and decision supports which utilizes instantaneous measurements from phasor measurments units (PMUs). These KTAs are modelled into the SG networks at both the distributuion and transmission domains [15].

The report in [16] shows the chronological sequence of Smart Electricity Systems comprising the infrastructure of the past, present and the future

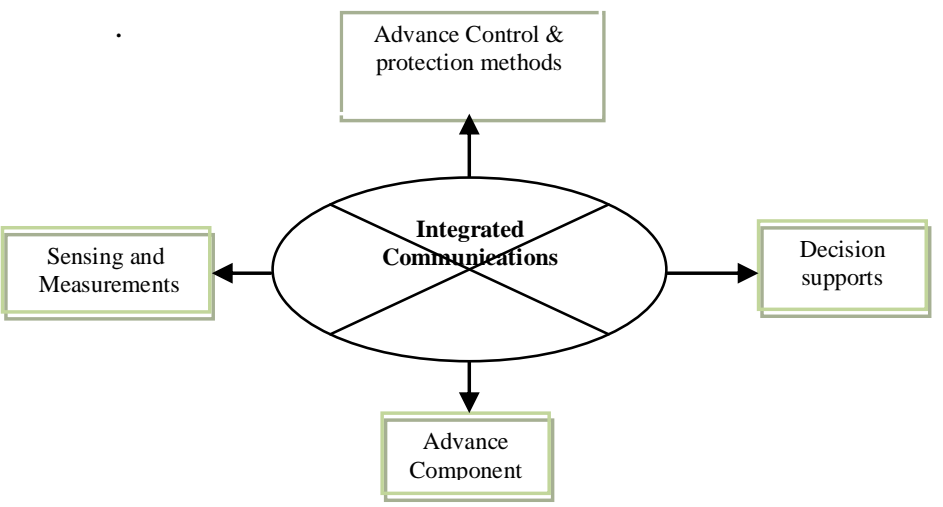

Fig.2. SG Key Technology Areas (KTAs)

Leveraging on Smart grid framework will not only guarantee stability in power provisioning but it will expedite efficiency in power generation, transmission and distribution. Also, Smart grids co-ordinate the needs and capabilities of all generators, grid operators, end-users and electricity market stakeholders to operate all parts of the system as efficiently as possible, minimizing costs and environmental impacts while maximizing system reliability, resilience and stability [16]. Figure 5 shows the generic Smart grid architecture modules with an additional SIM proposed in this work. Table 1 
presents the differences between current power grid network and the SG network. The components of figure 5 are discussed below viz:

1) Advanced Grid Components (AGC) allow for a more efficient energy supply, better reliability and availability of power. Components includes viz: advanced conductors and superconductors, improved electric storage components, new materials, advanced power electronics as well as distributed energy generation.

2) Advanced Control Systems (ACS) monitors and control essential elements of the smart grid. It supports computerbased algorithms which allow efficient data collection and analysis, provide solutions to human operators while acting autonomously. With ACS, errors and faults can be detected much faster than in traditional grids and outage times can be reduced.

3) Smart Devices and Metering (SDM) include ipads, android tablets, wireless sensor networks (WSN) used at transformers, substations and meters at client residents. These facilitates remote monitoring as well as enabling demand-side management allowing for real-time determination and information storage of energy consumption and provide the possibility to read consumption both locally and remotely. The meters detect fluctuations and power outages, permit remote limitations on consumption by customers and allows the meters to be powered down. This work will present the AMS model that fits into the SG framework in context.

4) Integrated Communication Technologies (ICT) carries information provided by SDM to be transmitted via a communication backbone. This backbone is characterized by a high-speed and two-way flow of information. The different communication technologies form the communication backbone are LAN, WAN, Core Networking, Security, Power system operations, Network management.

5) Decision Support and Human Interfaces (DSHI). This module will make data available to grid operators and managers in a user-friendly manner to support their decisions via software. It includes systems based on artificial intelligence and semi-autonomous agent software, visualisation technologies, alerting tools, advanced control and performance review applications as well as data simulation applications and geospatial information systems (GIS). The GIS provides geographic, spatial and location information and tailor this information to the specific requirements for decision support systems along the smart grid.

Smart Integrated Module (SIM) which is proposed to handle energy storage, and inverter technologies in the context of distributed generation. Figure 6 shows the proposed SG Power system architecture, however, some of the functionalities of the SIMs in figure 6 includes some functionalities in [14]: Static connection to the feeder, AC bus for AC loads, DC bus for DC loads and connections to energy storage and distribution generation, Voltage regulation in the steady state and in the transient mode, Fast real and reative power compensation, Fault detection and fault current limiting and isolation, Autonomous distributed intelligent control for shunt-time scale control, Coordinating an optimizaation for longer-time-scale control.
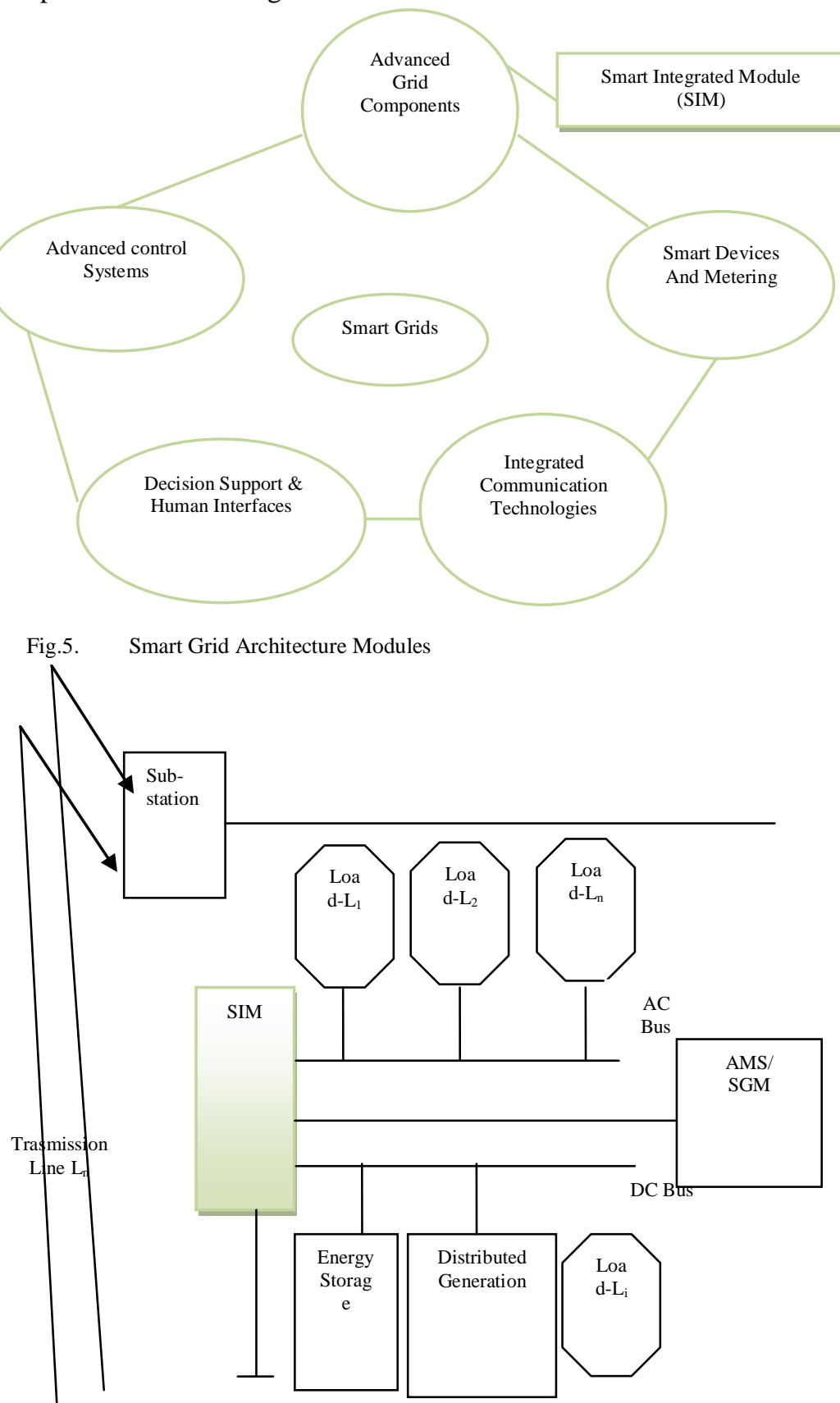

Figl6. A Conceptual Model of the SG Architecture For Dynamic Provisioning

In figure 6, the SIM contribute to energy loss reduction owing to:

1) Full Utilization of the distributed generation to reduce the real power flow on the grid

2) Provisioning of reactive power where it is consumed to reduce the reactance power flow on the grid. Following the role of power electronics in the voltage regulation functionality of SIMs, high-quality power 
3) supply at every load connection point is assured. This is because it will maintain an optimized voltage levels while compensating for voltage drops.

Besides, the energy storage functionality will provide a short to-medium term power supply buffer capacity so that customer's service will not be interrupted in the event of shortterm disruption on the distribution or transmission grid. This will create stability and relaxation in the transmission grid model. Future work will show the Advance metering sandbox (AMS) as a Smart grid meter which comprises of current and voltage sensors, partition dividers, signal conditioners, peripheral interface controller (PIC) with an embedded ADC and an LCD display. The AMS will leverage on the work in [17]. The design technique for digital meters is influenced by three major factors namely; desired device cost, efficiency and overall size, [17]. While the cost is influenced by users' general affordability, the efficiency and size must strictly comply with the SG standard. The Advanced metering Sandbox (AMS) will provide a wide range of functionalities viz:

1) Remote consumer price signals, which can provide time-of-use pricing information.

2) Ability to collect, store and report customer energy consumption data for any required time intervals or near real time.

3) Improved energy diagnostics from more detailed load profiles.

4) Ability to identify location and extent of outages remotely via a metering function that sends a signal when the meter goes out and when power is restored.

5) Remote connection and disconnection using mobile devices.

6) Losses and theft detection owing to the advance protection layer and alarm signalling.

7) Ability for a retail energy service provider to manage its revenues through more effective cash collection and debt management.

\section{SG Transmission Line Technical Limits to Power Transfers}

1) Conductor resistance, Temperature rating, and line sag. As a transmission line receives power, resistance inherent in the line conductor material converts some of the electrical energy into thermal energy, thereby increasing the line temperature. Line temperature increases as the current flowing through the line increases. Power transfers above a predetermined safe operating transfer limit can cause excessive conductor temperature, which causes line conductors to expand in length. Also, excessive operating temperatures may weaken the conductor, reducing its expected life. For underground conductors, high operating temperatures can damage insulation. Because aboveground transmission lines are suspended on fixed-distance tower structures, an expanding conductor manifests itself as sagging that reduces conductor distance to ground at the midpoint between towers. Because of line weakness at higher temperatures, this sagging can become permanent.

2) Voltage drop. The voltage drop increases as transmission line length increases. Similarly, the terminating voltage at the receiving end may vary above or below the recommended or nominal operating voltage, depending on the types of loads connected to the receiving end. Voltage constraints define the criteria needed to maintain receivingend voltages within specified bounds (usually $\pm 5 \%$ of the nominal voltage). Customer and utility equipment operates most efficiently when operated near the nominal voltage level.

3) Parallel flows. Because the electric power grid provides an interconnected set of transmission lines, the flows that one might expect to occur over the transmission line that directly connects Area A to Area B actually occur over all of the interconnected lines in varying amounts. It may be true that the direct line may transfer most (perhaps 60\%) of the power from Area A to Area B, but lines that are parallel to the direct line will also carry some portion of the power between the areas. Because electric power does not flow between areas in a simple manner that follows the contract path, the presence of parallel flows can cause a violation of thermal constraints on other lines in the system.

4) Synchronization. When two or more generators operate using the same interconnected transmission system, the generators must be synchronized. In the United States, this frequency is very near 60 hertz. Assuring synchronization maximizes power transfers and minimizes utility and customer equipment damage. In addition, synchronization helps to avoid transient instability and small-signal instability.

TABLE I. CURRENT POWER GRID VERSUS SG

\begin{tabular}{|l|l|}
\hline Current power grid network & New SG network. \\
\hline Centralized generation & Generation is Everywhere \\
\hline Power flows downhill & Power flows from Everywhere \\
\hline Utility controls connections & Anyone can participate \\
\hline It has a predictive behaviour & Random behaviour \\
\hline Not scalable and Intelligent & Very scalable and Intelligent \\
\hline
\end{tabular}

III. Methodology

In this section, we present a modelling approch to the proposed SG transmission subsystem. The work computes RLC parameters of overhead transmission line from its conductor characteristics and tower geometry. This will form the baseline for modeling N-phase asymmetrical lines in the context of SG Transmission design and deployments. MATLAB Simulink 2009b [20] tool was used to develop our intelligent fuzzy framework for the RPLS Algorithm General System Model and assumptions for RPLS for SG transmission line.

1) In our approach, four line parameters were considered in context, while generating their corresponding RLC matrix 
values. This includes: Case-1:Line_25kV_4wires.ie.(25-kVthree-phase distribution feeder with accessible neutral conductor.), Case-2:Line_315kV_2circuit.ie.(315-kV- threephase, double-circuit line using bundles of two conductors), Case-3:Line_500kV_2circuit.ie.(500-kV, three-phase, doublecircuit line using bundles of three conductors), Case4:Line_735kV.ie.(735-kV-three-phase, line using bundles of four conductors).

2) The framework is based on fuzzy logic controller using mamdani FIS.

3) The SIM works concurrently with the Line parameters.

4) The Output switching is the defuzzified the RLC_matrix.

\section{RPLS FUZZY LOGIC FRAMEWORK FORMULATION FOR TRANSMISSION LINE.}

\section{A. RPLS Modeling For GNIS Fuzzy Logic Controller}

In this framework, the considered computational variables/entities comprises of lines (case-1, Case-2, Case-3, Case-4, and Case-n+1), The SIM block and a defuzzified RLC_Matrix output. The priority computational scheme considers only fuzzy valid states for the input line parameters. All valid states are the fuzzy enable and as such solves the input matrix vectors.

\section{B. Fuzzification Fuzzy Optimization}

In the RPLS fuzzification process of the FLC design, let the four inputs Case-1, Case-2, Case-3, Case-4 be processed using four separate fuzzification blocks. In this process, there is need for memory elements $M_{e}$ to store the results of the computations. For a scalable design, the fuzzification block can have $X_{i} \ldots . X_{i+n}$ inputs and outputs with defined fuzzy value define in the inputs universe of discourse. However, in the design, the fuzzification process entails that for any single crisp value of the inputs Case-1, Case-2, Case-3, Case-4, only $\mathrm{N}$ adjacent values are significant (with non-zero membership values). We then configured the inputs in the FIS editor for the SG computational engine to generate the required matrix vectors of our line parameters. Figure 6 shows the block diagram of the RPLS fuzzy model. The middle block contains the rules which are formed using different combinations of the inputs supplied. The FIS editor displays the information about the fuzzy inference system.

Also from figure 6, the membership function editor of MATLAB environment was configured to process the inputs. The rule base in the MATLAB rule editor was configure for the inputs and now the defuzzified output is converted to surface diagrams and rule view for the computed RLC matrix vectors. The framework for RPLS using fuzzy logic framework is shown in figure 7.

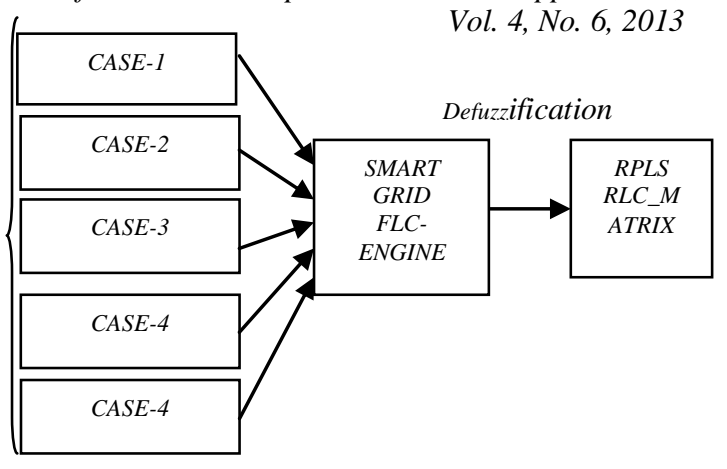

Figure 6: Block diagram of the RPLS Smart Grid fuzzy model

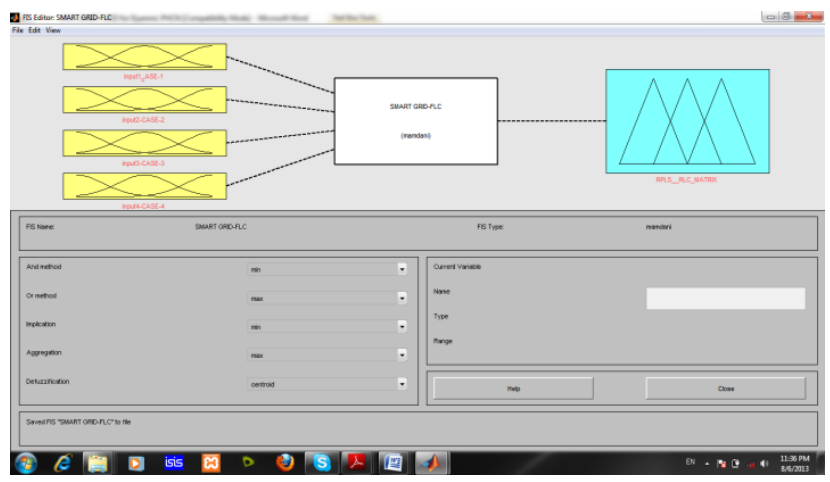

Fig.7. A Framework for RPLS using Mamdani fuzzy logic Structure.

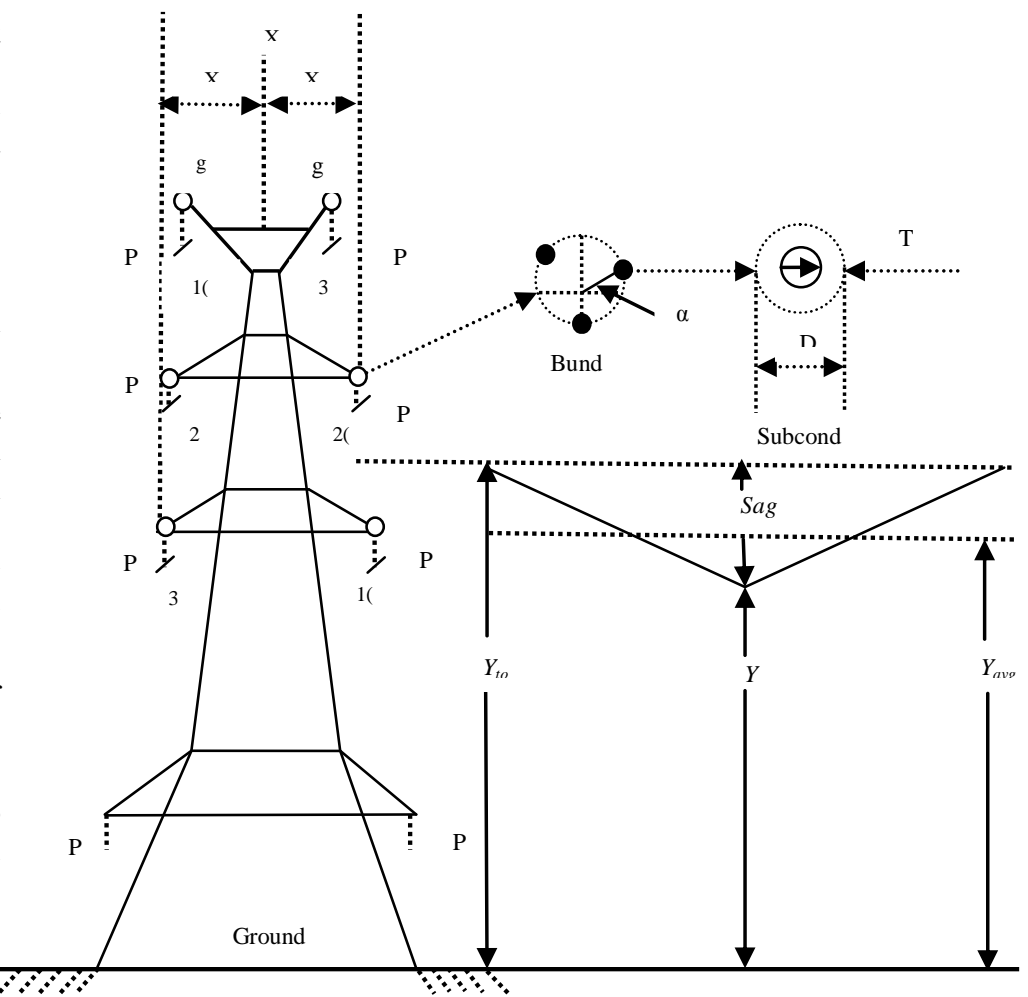

Fig.8. A Conceptual Model of the SG Transmission Line L (3-phase Double Circuit Line) 


\section{CSG Transmission Subsystem for RLC Parameters.}

\section{1) Modelling and Characterization}

Following our framework design in figure 7 , we then show the model of a SG transmission line with both line and tower geometry. The approach adopted in this paper follows the image conductor principle discussed in [19]. Using a proposed fuzzy RPLS scheme, any line transmission specification can be computed with ease in zero time.

By characterizing the input parameters both line and geometric tower components, the RPLS algorithm computes and displays the corresponding values. From figure 8, a conceptual model depicting only the transmission block with the tower and conductor geometry is presented. Recall that four line parameters were assumed for our matrix computation.

Let Case-1: represent a Line_25kV_4wires.ie.(25-kVthree-phase distribution feeder with accessible neutral conductor.), Case-2: represent a Line_315kV_2circuit.ie.(315$\mathrm{kV}$ - three-phase, double-circuit line using bundles of two conductors), Case-3: represent a Line_500kV_2circuit.ie.(500$\mathrm{kV}$, three-phase, double-circuit line using bundles of three conductors), and Case-4: represent a Line_735kV.ie.(735-kVthree-phase, line using bundles of four conductors).

Considering each of the cases, we characterized the model to achieve our objectives. Now, let the Horizontal position of the conductor in meters $=x_{h}$ and for symmetrical line, $\mathrm{x}=0$.

Frequency, Frq $=50 \mathrm{hz} ;$ Ground resistivity, $\operatorname{Rg}=100 \Omega$; Number of Conductor $\mathrm{Nc}=2$; Conductor internal inductance $=\mathrm{T} / \mathrm{D}$ ratio $=0.5$; Conductor skin effect $=$ Enable

Number of Phase Conductor/bundles $=3$; Number of ground wires $=2$; For conductor bundles, let Phase numbers $1,2,3=\mathrm{P}_{1}, \mathrm{P}_{2}, \mathrm{P}_{3}$; For a 3-Phase tripple circuit lines $\Rightarrow$ Circuit $1=\mathrm{P}_{1}, \mathrm{P}_{2}, \mathrm{P}_{3}$; Circuit $2=\mathrm{P}_{4}, \mathrm{P}_{5}, \mathrm{P}_{6}$; Circuit $3=\mathrm{P}_{7}, \mathrm{P}_{8}, \mathrm{P}_{9}$

Ground wires $=\mathrm{g}_{1}, \mathrm{~g}_{2}, \mathrm{~g}_{3} \ldots . . \mathrm{g}_{\mathrm{n}}$

Hence, $\mathrm{P}_{1}, \mathrm{P}_{2}, \mathrm{P}_{3}, \mathrm{P}_{4}, \mathrm{P}_{5}, \mathrm{P}_{6}, \mathrm{P}_{7}, \mathrm{P}_{8}, \mathrm{P}_{9}=\mathrm{A}, \mathrm{B}, \mathrm{C}, \mathrm{A}, \mathrm{B}, \mathrm{C}, \mathrm{A}, \mathrm{B}, \mathrm{C}$

For a 3-Phase Double circuit lines $\Rightarrow$ Circuit $1=\mathrm{P}_{1}, \mathrm{P}_{2}, \mathrm{P}_{3}$

Circuit $2=\mathrm{P}_{4}, \mathrm{P}_{5}, \mathrm{P}_{6}$

Figure 9 shows image conductor model for computing the resistance R, Inductance L, and Capacitance, C.

For a 3-phase double circuit line, the self and mutual resistance terms is given below:

$R n n=R i n t+\Delta R n n \quad \Omega / K m$.

$\mathrm{Rnm}=\Delta \mathrm{Rnm} \quad \Omega / K m$

The self and mutual Inductance terms is given below:

$$
\begin{gathered}
\operatorname{Lnn}=\operatorname{Lint}+\frac{\mu 0}{2 \pi} \cdot \log \cdot \frac{2 h_{n}}{r_{n}} \cdot \Delta L_{n n} \quad H / k m \ldots \ldots \\
L_{n m}=\frac{\mu 0}{2 \pi} \cdot \log \cdot \frac{D_{n m}}{d_{n m}}+\Delta L_{n m} \quad H / k m .
\end{gathered}
$$

The self and mutual Potential coefficients terms is:

$$
P_{n n}=\frac{1}{2 \pi} \cdot \log \frac{2 h_{n}}{r n} \mathrm{Km} / \mathrm{F} \text {. }
$$

$$
\begin{aligned}
P_{n m} & =\frac{1}{2 \pi} \cdot \log \frac{D_{n m}}{d n m} \mathrm{Km} / \mathrm{F} . \\
{[C] } & =[P]^{-1} \ldots \ldots \ldots \ldots \ldots \ldots \ldots
\end{aligned}
$$

Where, $\mu_{0}=$ Permeability of free space $=4 \pi \cdot 10^{-4} \mathrm{H} / \mathrm{Km}$, $\varepsilon_{0}=$ Permittivity of free space $=8.8542 \cdot 10^{-9} \mathrm{~F} / \mathrm{Km}$,

$\mathrm{r}_{n}=$ Radius of conductor $\mathrm{n} \mathrm{m}$ in meters, $\mathrm{d}_{n m}=$ distance between conductor $\mathrm{n}$ in meters, $\mathrm{D}_{n m}=$ distance between conductor $\mathrm{n}$ and image of $\mathrm{m}$ in meters, $\mathrm{L}_{n}=$ Avg height of conductor $\mathrm{n}$ above ground in meters, $\mathrm{R}_{\text {int }}, \mathrm{L}_{\text {int }}=$ Internal resistance and inductance of conductor, $\Delta R_{n n}, \Delta R_{n m}$ : Carson $\mathrm{R}$ correction terms due to ground resistivity, $\Delta L_{n n}, \Delta L_{n m}$ : Carson L correction terms due to ground resistivity.

The conductor self inductance is computed from the magnetic flux circulating inside and outside the conductor, and produced by the current flowing in the conductor itself. The part of flux circulating inside the conducting material contributes to internal inductance $\mathrm{L}_{i n t}$, which is dependant on the conductor geometry. Assuming a hollow or solid conductor, the internal inductance in the model is computed from the T/D ratio where $\mathrm{D}$ is the conductor diameter and $\mathrm{T}$ is the thickness of the conducting material ( As shown in figure $8)$.

Assuming the vertical position of the conductor (at the tower) wrt ground in meters $=y_{v}$; Vertical position of the conductor wrt ground at mid span in meters $=y_{\min }$

Line parameters via Load $=750 \mathrm{Kv}, 500 \mathrm{Kv}, 450 \mathrm{Kv}$, $315 \mathrm{Kv}$ and $25 \mathrm{Kv}$. The Average Height of the conductor is given by :

$\mathrm{Y}_{\mathrm{avg}}=\mathrm{Y}_{\min }+\mathrm{Sag} / 3=\left[2 \mathrm{Y}_{\min }+\mathrm{Y}_{\mathrm{towr}}\right] / 3$

Where, $\mathrm{Y}_{\text {towr }}=$ Height of conductor at tower, Ymin $=$ Height of $m$ uctor at mid span, and $\operatorname{Sag}=\mathrm{Y}_{\text {towr }} \mathrm{Y}_{\text {min }}$.

Fig.9. Image conductor model

\section{IMPLEMENTATION RESULTS}

The MATLAB 7.7.0 R2008b [20] was configured while loading the three case scenriors to compute the RLC line parameters matrix equivalents. First of all, we define the input line geometry and the conductor bundle characteristics (as shown in figure 10a and figure 10b) for the various cases in the MATLAB simulink environment and consequenly runing the simulation and exporting the computed values to the command prompt for collection and data analysis. Below is 
the RLC matrix results generated from the MATLAB Simulink.

$\begin{array}{ccc}\text { R_matrix }= \\ 0.0890 & 0.0790 & 0.0773 \\ 0.0790 & 0.0915 & 0.0790 \\ 0.0773 & 0.0790 & 0.0890 \\ \text { L_matrix }= \\ 0.0016 \quad 0.0008 & 0.0006 \\ 0.0008 & 0.0016 & 0.0008 \\ 0.0006 & 0.0008 & 0.0016 \\ C \_ \text {matrix }= \\ 1.0 e-007 * \\ 0.1166 & -0.0213 & -0.0058 \\ -0.0213 & 0.1212 & -0.0213 \\ -0.0058 & -0.0213 & 0.1166 \\ R 1= & 0.0114 & 0.2466 \\ \text { L1 }= & 0.0009 & 0.0031 \\ 1.0 e-007 * & 0.1343 & 0.0859\end{array}$

The positive-sequence and zero-sequence parameters of the transposed line are displayed in the Display Results window in the R1 [in $\Omega / \mathrm{km}$ ], L1 [in $\mathrm{mH} / \mathrm{km}$ ], $\mathrm{C} 1[\mathrm{in} \mathrm{nF} / \mathrm{km}$ ] vectors.

\section{CONCLUSION AND FUTURE WORK}

This paper have presented $\mathrm{SG}$ as a sustainable power model for the Nigeria environment while proposing a conceptual SG architecture that took cognizance of three fundamental research elements viz: the transmission line modelling, the SIM and the advanced metering sandbox. This paper outlined the current issues with the existing methods of solving transmission line parameters. In a SG design, a proposed RPLS offers an efficient method of computing the parametric matrices. Handling complex transmission line specifications can better be addressed with RPLS approach which results in less computational analysis by the system planner.

Furthermore, we argue that Smart Grid presents opportunities for utilities and consumers to benefit from efficient management of energy and advanced technology, equipment and devices under well designed transmission, and distribution infrastructures.Besides, it offers significant opportunities to intelligently manage the available energy options and resources by potentially eradicating monopoly, while integrating renewable and non-renewable generation sources into the electricity grid and enabling consumers to better manage their energy consumption. Its challenges have been outlined in [21]. Moreover, this work considered a method of modelling the transmission line parameters and quickly computing their values for system designers so as allow for futuristic prediction of the transmission grid requirements. By using power line parameter computation in MATLAB Simulink, it was shown that it is possible to compute the RLC line parameters very conveniently.

In the future, we are going to investigate: $i$ ) the use of RPLS algorithm for arbitary computations, ii) the optimal processing algorithm in order to provide the greatest correlation and accuracy, iii) complete the design and implementation of the AMS for the proposed Smart architecture and finally, various validation analysis will be presented to validate our proposal.

\section{REFERENCES}

[1] Aaron St. Leger, "Transmission Line Modeling for the Purpose of Analog Power Flow Computation of Large Scale Power Systems", M.Sc, July, 2005.

[2] Mehmet Salih MAM'IS, Asım KAYGUSUZ, Muhammet K"OKSAL, "State variable distributed-parameter representation of transmission line for transient simulations" Turk J Elec Eng \& Comp Sci, Vol.18, No.1, 2010, doi:10.3906/elk-0905-2

[3] A. R. Bergen and V. Vittal, Power System Analysis, 2nd ed: PrenticeHall, 2000.

[4] Mohazzab JAVED, Hussain AFTAB, Muhammad QASIM, Mohsin SATTAR, "RLC Circuit Response and Analysis (Using State Space Method)", IJCSNS International Journal of Computer Science and Network Security, VOL.8 No.4, April 2008.

[5] Jeffrey A. Davis and James D. Meindl, "Compact Distributed RLC Interconnect Models-Part I: Single Line Transient, Time Delay, and Overshoot Expressions" IEEE TRANSACTIONS ON ELECTRON DEVICES, VOL. 47, NO. 11, NOVEMBER 2000

[6] J.C. Molburg, J.A, Kavicky, K.C Picel, “ The Design, Construction, and Operation of long Distance High

[7] Voltage Electricity transmission Technologies "Argonne National Laboratory, Nov, 2007.

[8] Ravi Kaushal, “ Challenges Of Implementing Smart Grids In India",2011

[9] Whitepaper-Technology Roadmap, Smart Grids, www.iea.org/about/copyright.asp,2011

[10] Whitepaper- Smart Sensor Networks: Technologies and Applications for Green Growth, December 2009

[11] Climate Group, The and GeSI (2008), SMART 2020: Enabling the Low Carbon Economy in the Information Age, www.theclimategroup.org/assets/resources/publications/ Smart2020Report.pdf.

[12] Adam, R. and W. Wintersteller (2008), From Distribution to Contribution. Commercialising the Smart Grid, Booz \& Company, Munich

[13] Miller, J. (2008), “The Smart Grid - How Do We Get There?", Smart Grid News, June 26.

[14] Electric Power Research Institute (EPRI, 2005), IntelliGridSM - Smart Power for the 21st century, www.epriintelligrid.com/intelligrid/docs/Intelligrid_6_16_05.pdf.

[15] Enrique. S. et al, Gettin SMART, IEEE power and Energy magazine, march 2010,pp.11-18.

[16] Stanley I.H et al, The future of poer transmission, IEEE power and Energy magazine, march 2010,pp.4-10

[17] Whitepaper-Technology Roadmap, Smart Grids, www.iea.org/about/copyright.asp,2011

[18] M.C. Ndinechi, O.A. Ogungbenro, K.C. Okafor, "Digital metering system: a better alternative for

[19] Electromechanical energy meter in Nigeria" International Journal Of Academic Research, Vol.3.No. 5. September, 2011, I Part.

[20] EIA, 2002, Upgrading Transmission Capacity for Wholesale Electric Power Trade, Energy Information Administration, U.S. Department of Energy, Washington, D.C. 
[21] Available http://www.eia.doe.gov/cneaf/pubs_html/feat_trans_capacity/w_sale.htm 1. Accessed February 12, 2007.

[22] Dommel, H., et al., Electromagnetic Transients Program Reference Manual (EMTP Theory Book), 1986

[23] Mathworks. 2008. http://www.mathworks.com
[24] Udeze Chidiebele .C, Prof. H.C. Inyiama, Okafor Kennedy .C, Dr C.C. Okezie, Smart Grids: A New Framework for Efficient Power Management in Data Center Networks. International Journal of Computer Science and Application (IJACSA) Volume 3, Number 7 (2012), pp 59-66. 